\title{
Effect of cement on compressibility and microstructure of tropical peat
}

\begin{abstract}
Peats are geotechnically problematic soil due to their high compressibility and low shear strength. Cement is widely used for the stabilization of peat by deep mixing method (DMM). This paper presents the results of the model study of compressibility property of peats stabilized with cement columns formed by DMM. The results of consolidation test, scanning electron micrographs (SEM) and energy dispersive x-ray spectrometer (EDX) showed that the compressibility of peats can be improved significantly by the installation of cement stabilized columns. The amount of cement used to form the column was observed to influence the engineering behaviour of treated tropical peats and it had more influence on sapric peat than on hemic and fibrous peats.
\end{abstract}

Keyword: Cement column; Compressibility; Energy dispersive X-ray; Peat; Scanning electron micrograph 